\title{
Aproximación a la danza en la antigüedad hispana. Manos entrelazadas
}

\author{
Raquel Castelo Ruano*
}

La danza es considerada un arte natural y primordial. Tiene un valor simbólico, ya que expresa un sentimiento y un estado emocional del alma. Desde sus comienzos, el baile fue la ejecución artística para la que el hombre estuvo mejor dispuesto (Bonilla, L., 1964, 9).

En la Península Ibérica disponemos de numerosos documentos iconográficos y algunas fuentes escritas (Estrabón, III, 3, 7) que nos permiten adentrarnos en el espacio y en el tiempo donde se desarrollaron estas manifestaciones. Las escenas de baile son muchas y variadas, falta un estudio de conjunto que permita una valoración más completa. Nuestra vinculación por razones profesionales con el tema ${ }^{1}$, nos permite brevemente acercarnos a una de estas danzas en las que siempre intervienen varios individuos y donde es frecuente el contacto de sus manos, manifestación de la unión de los intérpretes, conocida con el nombre de "Danza de manos entrelazadas".

\section{ICONOGRAFIA DE LA DANZA}

Pasaremos brevemente a revisar una de las muchas representaciones que ilustran el tema: I) Pinturas rupestres postpaleolíticas; II) Estelas

\footnotetext{
- Profesora Asociada Departamento de Prehistoria y Arqueologia U.A.M. Madrid

Diplomada en ballet clásico por el Real Conservatorio de Arte dramático y Danza de
} 
del Bronce Final; III) Objetos de adorno de la Primera Edad del Hierro, y IV) Representaciones en algunos fragmentos cerámicos de la Segunda Edad del Hierro.

\section{I) PINTURAS RUPESTRES POSTPALEOLITICAS}

Los estudios realizados por $P$. Acosta sobre pintura parietal han permitido a la autora interpretar como danzas algunas escenas con figuras humanas esquemáticas, como en el caso de la Cueva de las Mujeres o Cueva Ahumada de Cádiz (Acosta, 1986, 168).

Bailes de manos entrelazadas se han documentado en algunas zonas de Andalucia, Badajoz, Ciudad Real y Soria.

1. Andalucía. - En el abrigo de Peñas Cabrera (Casa Bermeja, Málaga) el grupo está formado por seis figuras humanas unidas entre sí y dispuestas mujer-hombre-mujer-mujer-hombre-mujer. Los personajes danzan alrededor de un ser o ente de carácter sagrado o divino, a quien estaría dedicada la danza (fig. 1). En los Cholones (Córdoba), un pequeño número de figuras humanas femeninas, dos de las cuales van unidas de la mano, danzan en torno a un personaje central masculino (Barroso Ruiz y Medina, 1988, 61-72) (fig. 2); en Cueva de las Mujeres o Cueva Ahumada (Cádiz) se representaron tres figuras femeninas, dos de ellas llevaban las manos unidas según el calco realizado por Cabré y Hernández Pacheco (Morán Cabré, 1973, 165) (fig. 3).

2. Badajoz. - En las Viñas de Alange se han representado figuraciones bitriangulares semejantes a las realizadas en Cueva Ahumada, Io que nos hace establecer la hipótesis de que estuvieran ejecutando un baile con las manos unidas (fig. 4).

3. Ciudad Real.-En los Gavilanes se han representado de forma muy esquemática los llamados "hombres barra" que podrian ser miembros integrantes de danzas en línea con las manos cogidas (fig. 5).

4. Soria.-En el covachón del Puntal, en el Barranco de Valansadero (Soria), se ha representado un grupo de siete personajes enlazados por las manos que bien podian ejecutar la danza objeto de nuestro estudio (Lucas, 1979, 360). (fig. 6).

5. Lérida.-En las pinturas rupestres de Cogull, el grupo pictórico está formado por "diez personajes bien definidos, distribuidos de la manera siguiente: cinco mujeres a mano izquierda y otras cuatro a la dere- 


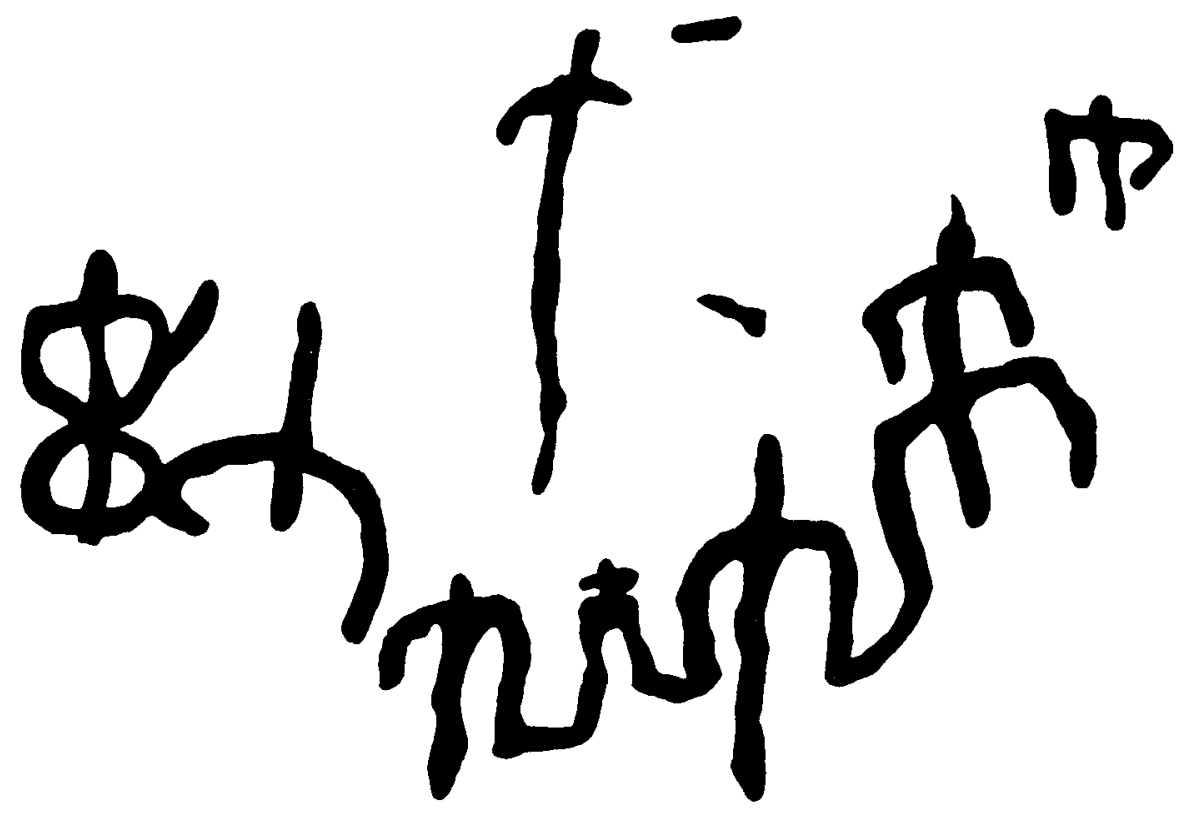

Fig. 1. Abrigo de Peñas Cabrera (Casa Bermeja, Málaga). Según Barroso.

cha de un hombre colocado en el centro de un corro formado por dichas mujeres. Una de las cinco damas del grupo primero está representada en actitud de saltar, mientras que las otras cuatro del segundo grupo parecen huir del hombre que ocupa el centro, dándose las manos y formando parejas. Las damas visten faldas acampanadas, desnudas de cintura hacia arriba” (Ruano, 1977, 44) (fig. 7).

Los paralelos de estas pinturas los encontramos en Asia Occidental, en torno al $\mathrm{V}$ milenio a.C., decorando los vasos cerámicos de Tellhalaf, Tchechmé-Ali y Sialk (Barroso Ruiz, Medina, 1988, 12).

Las mismas figuraciones de hombres y mujeres las encontramos en el mundo mesopotámico, y concretamente en la pintura vascular fechada en el IV milenio a.C., en los vasos cerámicos de Samarra y Rey (Parrot, 1960, 46-51) (fig. 8). 

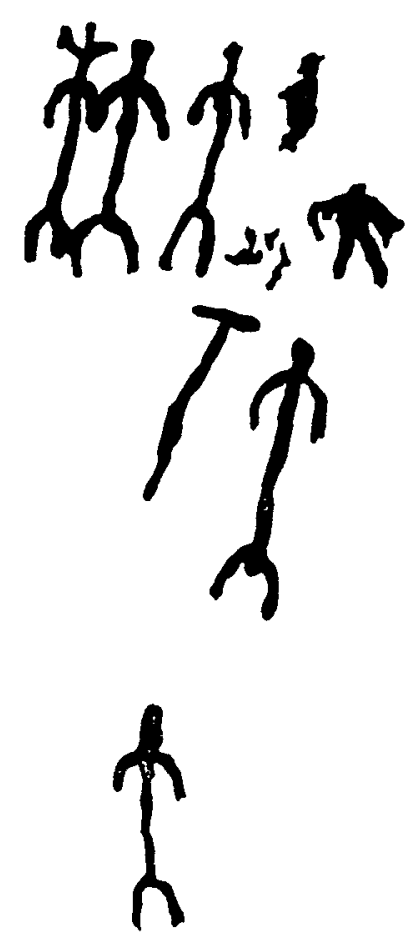

Fig. 2. Cueva de los Chalones (Priego, Córdoba). Según Bernier y Fortea.

II) ESTELAS DEL BRONCE FINAL

Representaciones de individuos alineados se encuentran en dos estelas del suroeste peninsular, procedentes de Ategua (Córdoba) y Aldea del Rey (Ciudad Real)

1. Ategua (Córdoba).-La estela está decorada con varias escenas: prothesis (exposición del cadáver), sacrificio de animales, personaje con carro y dos grupos de cuatro y tres personajes cogidos de las manos que fueron considerados como la representación de los hijos del difunto, pero sin duda se trata de personas que ejecutan una danza fúnebre (Bendala, 1979, 191) (fig. 9).

2. Aldea del Rey (Ciudad Real).-Presenta otra escena de danza, en este caso situada en la parte superior. En ella participan cuatro personajes de los que el primero seria un guerrero, si es que realmente empuña una lanza y escudo, o un corifeo si llevara bastón. El cuarto 

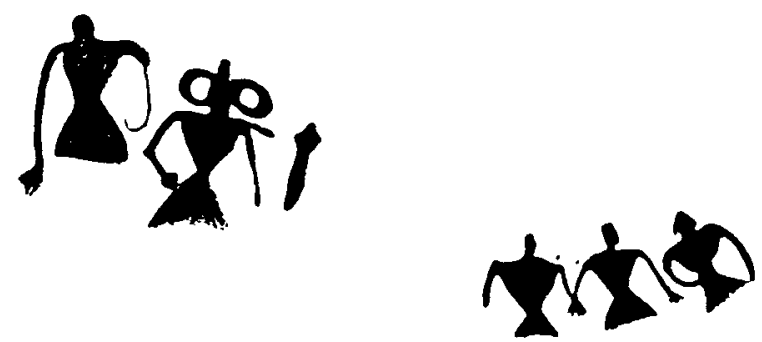

Fig. 3. Cueva de la Ahumada o de las Mujeres (Cádiz). Según Cabré y Hernández Pacheco.

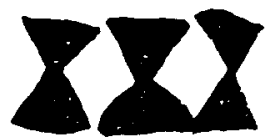

Fig. 4. Viñas de Alange (Badajoz). Según Brevil.
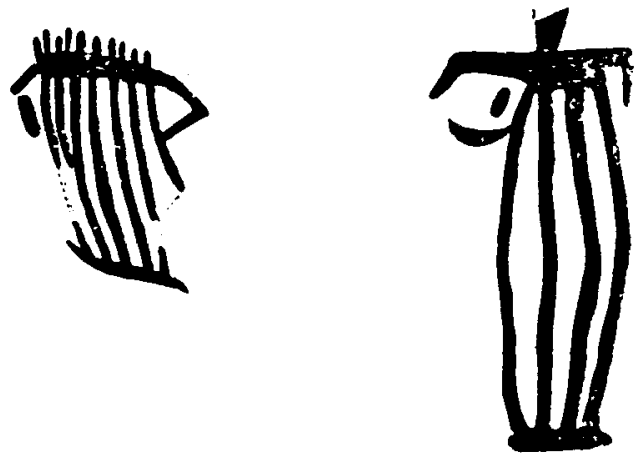

Fig. 5. Los Gavilanes de Font Caliente (Ciudad Real). Según Brevil. 


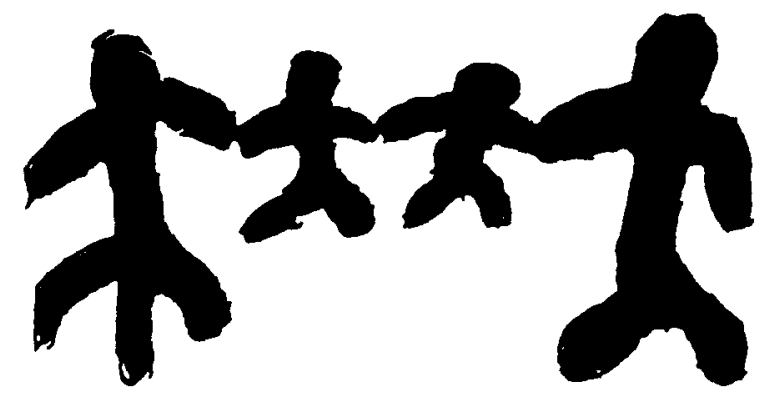

Fig. 6. Covachón del Puntal (Soria). Según Ortego.

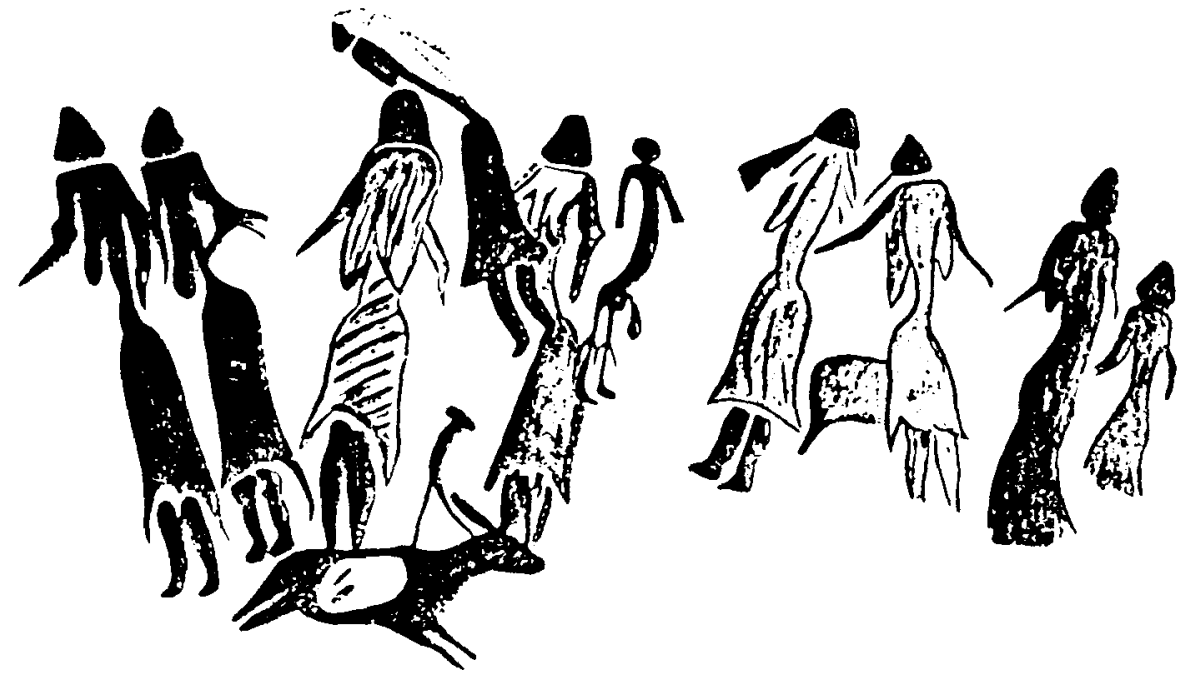

Fig. 7. Cogull (Lérida). Según Brevil y Cabré.

personaje podria ser femenino; como sugiere la labra más ancha del cuerpo se habria intentado representar la vestidura talar del personaje femenino (Valiente Malla y Prado Toledano, 1979, 28-29) (fig. 10).

Este tipo de danza colectiva se documenta en el siglo XIV a.C., en el MR III, en una terracota policromada procedente de Palaicastro. En ella se han representado tres mujeres sosteniéndose por los hombros que danzan en círculo en torno a una tañedora de lira, acompañada por una paloma (Faure, 1984, 273, y Zenos, 1956, 479).

En el periodo geométrico griego se documentan tanto en las fuentes literarias como en las arqueológicas. En las literarias, la existencia de la 

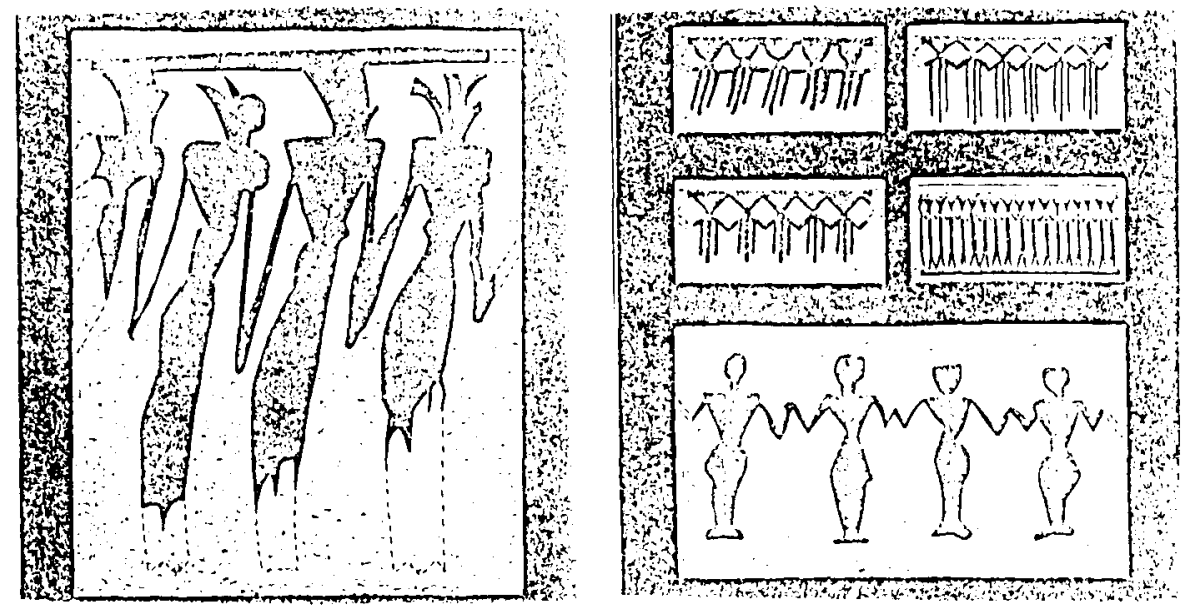

Fig. 8. Cerámicas de Samarra y Rey (Mesopotamia). Según Parrot.

danza se recoge en el canto XVII de la lliada. En él se atribuye a la isla de Creta la invención de la primera danza de los jóvenes, en círculos y filas, al son de la phorminx: ... uel ilustre cojo (Vulcano) de ambos pies puso luego la danza como la que Dédalo concertó en la vasta Cnoso en obsequio de Ariadna, la de lindas trenzas. Mancebos y doncellas hermosas, cogidos de las manos se divertian bailando: éstas llevaban vestidos de sutil lino y bonitas guirnaldas, y aquéllos, túnicas bien tejidas y algo lustrosas, como frotadas por aceite, y sables de oro suspendidos de argénteos tahalies. Unas veces, moviendo los diestros pies, daban vueltas a la redonda con la misma facilidad con que el alfarero aplica su mano al torno, $y$ en otras ocasiones se colocaban en hileras y bailaban separadamente. Un gentio inmenso rodeaba y se holgaba en contemplarlo. Un divino aedo cantaba acompañándose de la cítara y en cuanto se oía el preludio dos saltadores hacian cabriolas en medio de la muchedumbre...".

La escena, descrita minuciosamente por Homero, se ha representado en una de las franjas decorativas del llamado Vaso Françoise, cratera de figuras negras del siglo vi a.C., conservado en el Museo Arqueológico de Florencia. Su pintor, Clitias, representó en él el desembarco de Teseo al llegar a su patria y a varios hombres y mujeres cretenses con las manos entrelazadas (Boardman, 1974, 42, y Maffre, 1984, 52).

En las fuentes arqueológicas se documentan en los vasos cerámicos estudiados por Coldstream, Wegner y Courbin (Coldstream, 1968; Wegner, 1949, y Courbin, 1966) (fig. 11). 


\section{III) OBJETOS DE ADORNO DE LA PRIMERA EDAD DEL HIERRO}

En la Primera Edad del Hierro, la danza de manos entrelazadas se ha figurado en dos fragmentos de cinturón de chapa de bronce encontrados por el Marqués de Cerralbo en el transcurso de las excavaciones de la necrópolis de Alpanseque (Soria).

La decoración de estos dos fragmentos es sorprendente. Entre los motivos ornamentales destacan una serie de figuras humanas filiformes encadenadas que de cuatro en cuatro se localizan en los lados más estrechos (Cabré y Morán, 1975, 605).

\section{IV) PINTURA VASCULAR IBERICA}

En el mundo iberico conocemos a través del texto de Estrabón la existencia de una danza de manos entrelazadas: ... «los serranos, durante la bebida, bailan en rueda acompañados por flauta y corneta, haciendo saltos y genuflexiones. En Bastetania bailan hombres y mujeres cogiéndose de las manos..." (Estrabón, III, 3, 7).

Las danzas de las que nos habla Estrabón (III, 3, 7) para la Bastetania se documentan en Edetania, a través de los vasos de San Miguel de Liria (Valencia). Estas piezas cerámicas son de gran interés, ya que dan a conocer muchos de los aspectos de la vida cotidiana del pueblo ibérico. El artista que realizó estos vasos consiguió dar a la decoración cierto argumento, aunque se nos escapa su significación más profunda (Blázquez et alii, 1980, 271-272).

Las pinturas realizadas en fragmentos de La Alcudia y Monastil completan este panorama.

1. Vasos de San Miguel de Liria (Valencia).-Se han representado escenas de danzas en los siguientes fragmentos cerámicos: a) calatos de cuerpo cilíndrico y ala plana horizontal; b) fragmento de enocoe con el cuello, boca y asa de doble nervadura; c) tinaja de cuerpo bitroncocónico, de cuello reentrante con reborde y asas en cinta; d) fragmento indeterminado.

a) Calatos de cuerpo cilindrico y ala plana horizontal. - Encontrado en los departamentos números 12 y 13 (Ballester Tormo et alii, 1954, 36 ). El friso central presenta una decoración con escena de danza bise- 


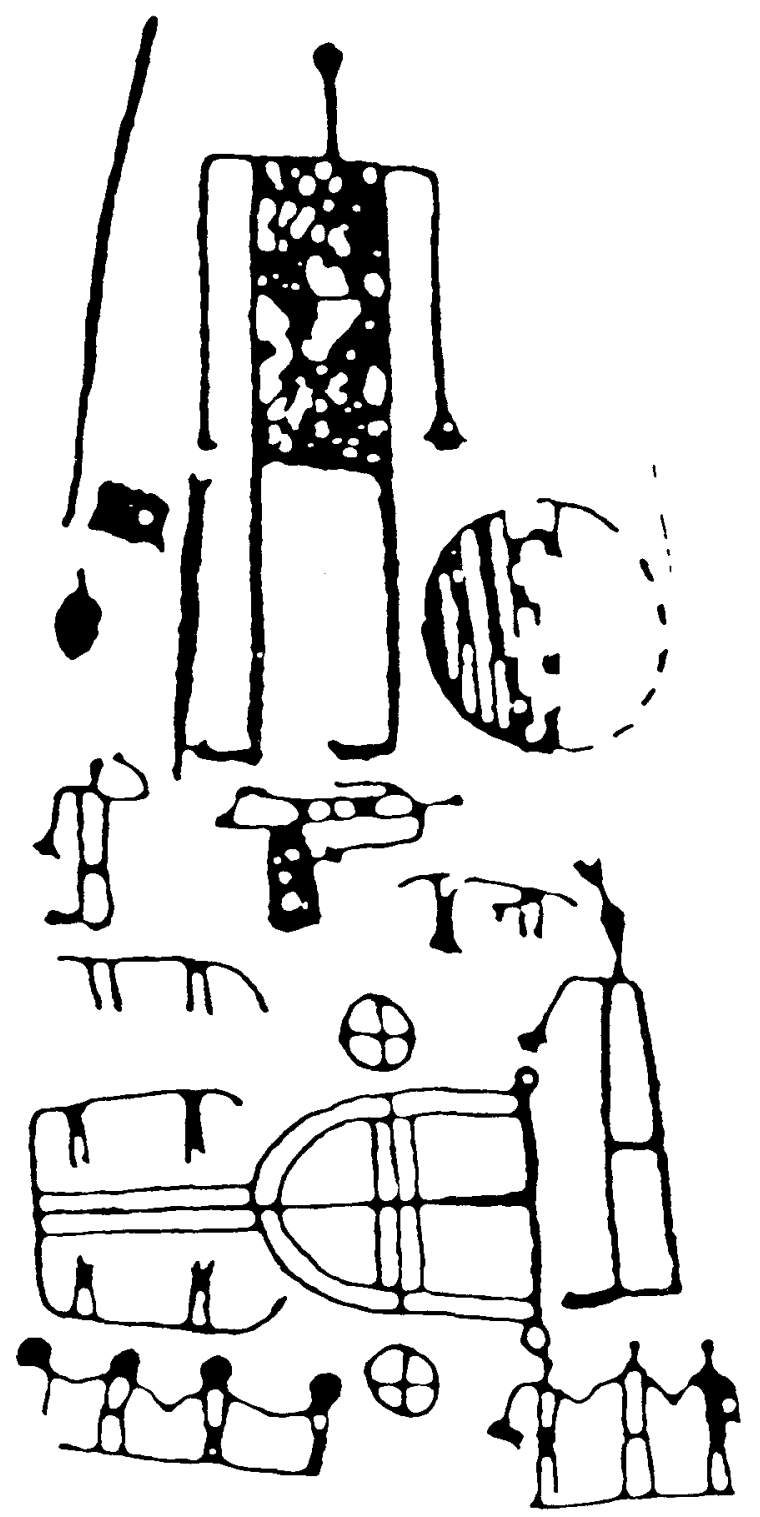

Fig. 9. Estela de Ategua (Córdoba). Según Bendala. 


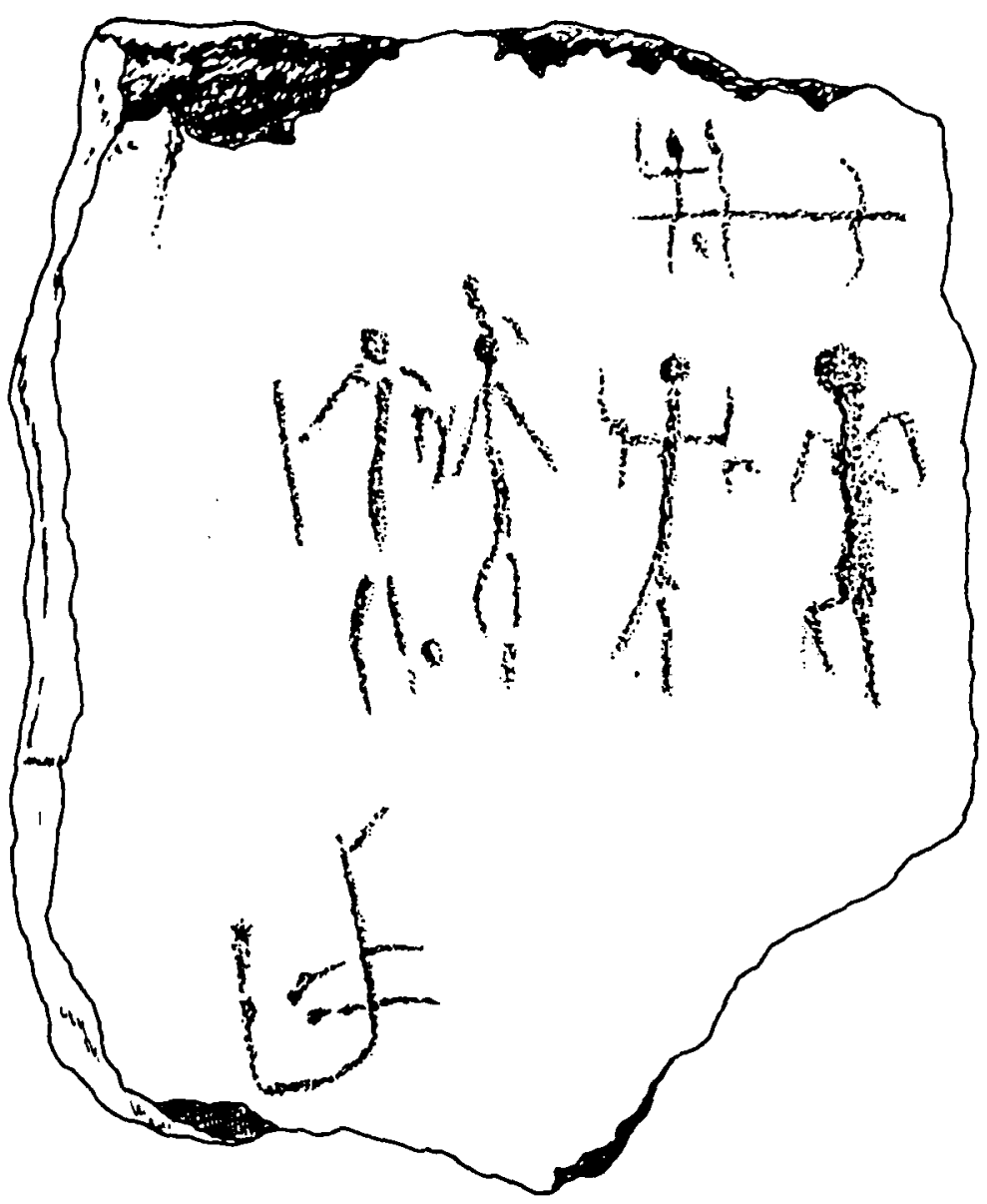

Fig. 10. Estela de Aldea del Rey III (Ciudad Real). Según Valiente Malla y Prado Toledano.

xual a la derecha, en la que toman parte tres varones y cuatro mujeres precedidos de un auletris que tañe la doble flauta, y un auleter que lleva una flauta simple (Castelo, 1989, 12-13). Los varones, ataviados con calzón ancho y túnica sin mangas, ceñida por cinturones y cruzadas por dos tirantes en el pecho, van tocados posiblemente con un casco con cimera. Se les ha representado queriendo dar la sensación de movimiento, con el pie izquierdo ligeramente levantado del suelo, como si estuvieran saltando sobre su pierna derecha. El primer danzante lleva el brazo izquierdo hacia delante como consecuencia del impulso que toma para 


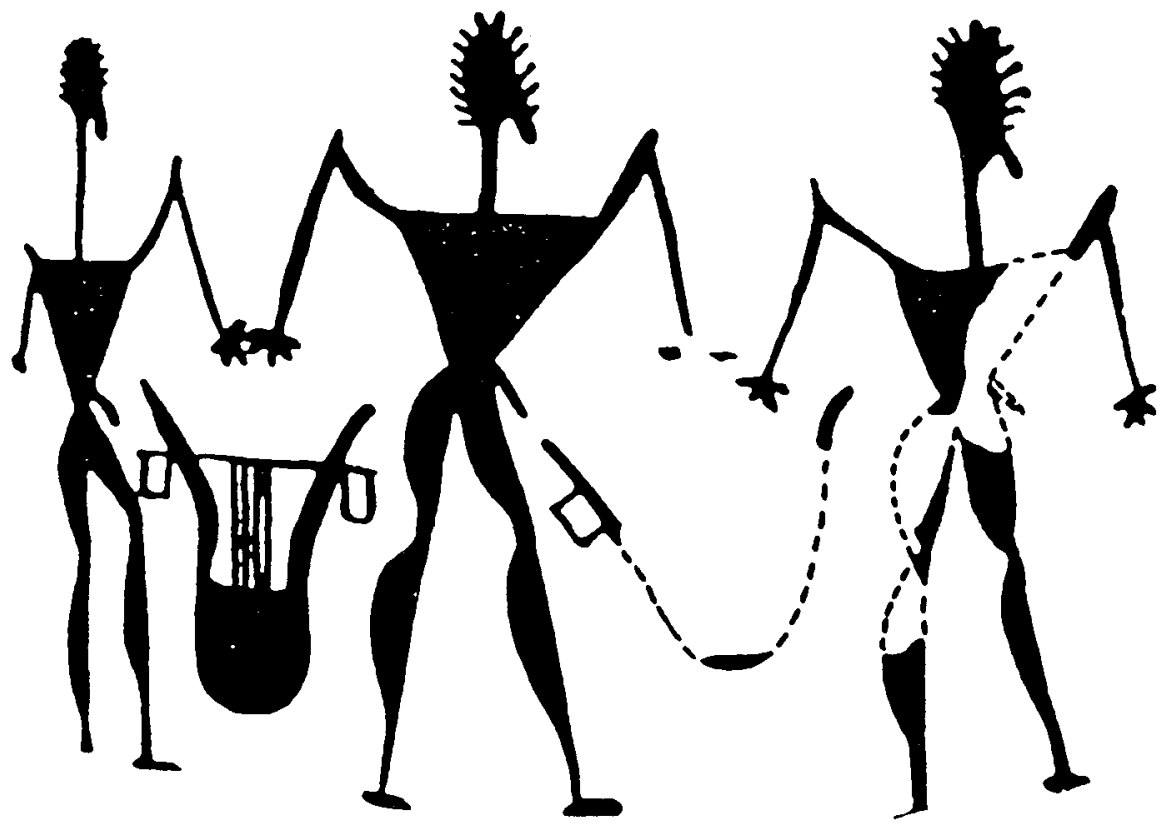

Fig. 11. Vaso Lacónico (Atenas).

elevarse del suelo. El segundo bailarin parece agarrar al primero por el codo y no por la mano. El tercero coge al anterior por la mano.

Las mujeres visten trajes acampanados de manga larga y escote a ras del cuello, dejando ver los pies al descubierto, decorados en su parte inferior con una cenefa ajedrezada. Llevan como tocado un casquete, con rizo bajo la oreja, que cubre la frente y no deja ver el cabello (Maestro Zaldivar, 1975, 165-172). La mujer que le corresponde unirse al varón exhibe un distintivo de mayor categoría que el resto de sus compañeras, lo que ha hecho pensar a la doctora Lucas en la posibilidad que se estuviera representando una ceremonia nupcial y no una danza funeraria (Lucas, 1979, 362). Para Uriel, el pectoral de la primera danzante nos indicaría su alta jerarquía interpretándolo como el haz de rayos de Zeus, a quien este mismo autor considera dios tutelar de los edetanos (Uriel, 1946, 95-110).

Las cuatro mujeres llevan los pies pegados al suelo, parece que los estuvieran arrastrando o dando pequeños pasos, produce sensación de deslizamiento. Como vimos en los danzantes masculinos, la segunda bai- 
larina agarra por el codo a la mujer que exhibe el distintivo de mayor categoría (fig. 12).

b) Fragmento de enocoe con el cuello, boca y asa de doble nervadura.-Entre los motivos decorativos que forman parte de la ornamentación, debemos destacar tres cabezas de damas de perfil mirando hacia la derecha: los ojos son pequeños circulitos con punto central y con finas cejas onduladas, se tocan mediante algo a modo de mitra o peineta puntiaguda muy echada hacia atrás, rematada por tres rizos. Por lo que se deduce de la figura central, el vestido termina en cuello alto ceñido. Llevaban una flor en la mano (Ballester Tormo, 1954, 40). (Fig. 13).

Por la disposición en la que se encuentran representadas bien podian estar ejecutando la danza de manos entrelazadas que hemos visto en el vaso anterior, pero en este caso sostendrian entre sus manos flores o ramos, al igual que en algunas figuraciones de la pintura vascular del geométrico griego.

Tres figuras femeninas que se dan la mano están documentadas en un par de brazaletes de oro procedentes del ajuar de la cámara del fondo de la tumba Regolini Galasi, necrópolis del Sombo, Cerveteri (Rosati y Bonagelli, 1983, 41).

c) Tinaja de cuerpo bitroncocónico, cuello reentrante con reborde y asa en cinta.-Carece de base por rotura. Fue encontrada en el departamento número 16 (Ballester Tormo, 1954, 51). De la decoración debemos destacar la que se ha representado en el friso principal. Se trata de una danza ritual, compuesta por una figura fálica desnuda, que revive, según $R$. Lucas, las danzas fálicas de los tiempos remotos, delante de la cual se ha colocado un grupo de cuatro damas cogidas de la mano, tocadas con alta peineta y vestidas con larga túnica que se dirigen a la derecha, en donde, tras una rotura del vaso, se encuentra otra dama que ofrece un ave a figura masculina que lleva en su mano izquierda una

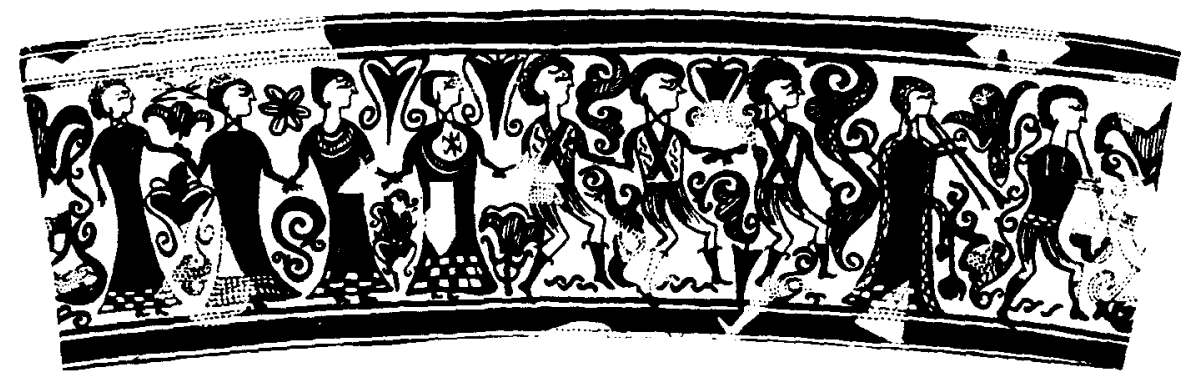

Fig. 12. Kalasthos, San Miguel de Liria (Valencia). Según Ballester Tormo. 


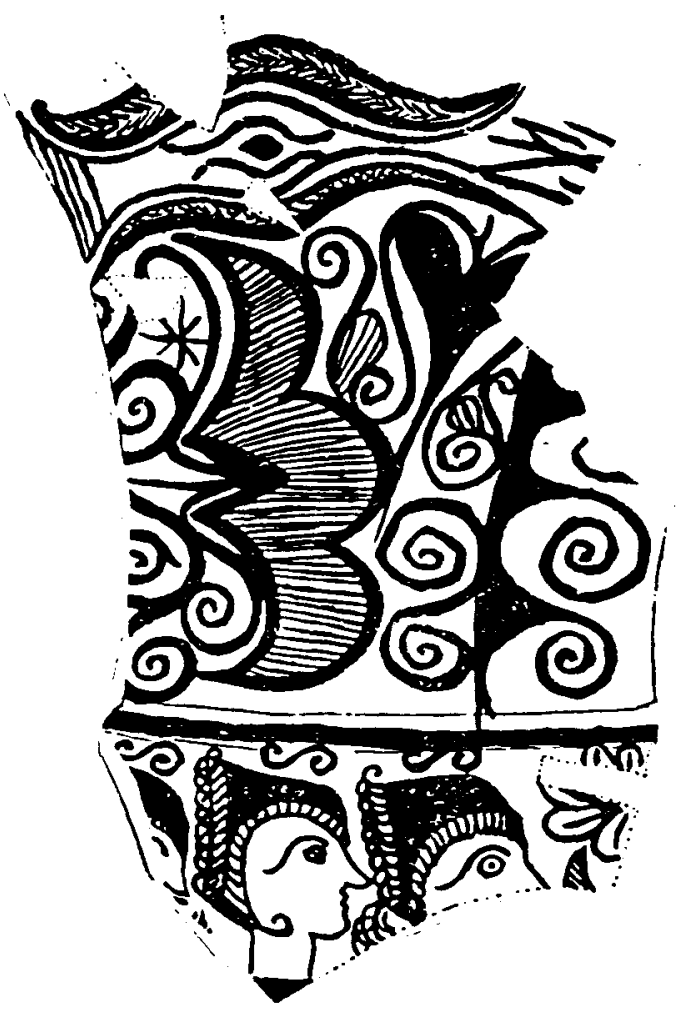

Fig. 13. Fragmento de enocoe. San Miguel de Liria (Valencia). Según Ballester Tormo.

lanza de punta triangular. Para R. Lucas se trata de un intercambio u ofrenda de elementos (puñal y paloma) entre individuos de distinto sexo, como si se tratara de la donación mutua o de un contrato simbólico (Lucas, 1979, 362). Tras esta escena, el vaso presenta una rotura, y seguidamente hay una escena en la cual el guerrero cae atravesado por una lanza (fig. 14).

d) Fragmento indeterminado.-Bajo una franja o filete se desarrolla una escena de danza bisexual a la derecha. En el fragmento se observan un hombre y tres mujeres. La figura masculina va vestida con largo jubón con mangas, sostenido por tirantes que se cruzan en el pecho, tocado con casco y armado con falcata. Es la única vez que se representa a un "danzante» con todas las armas ofensivas. Al no conservarse las extre- 


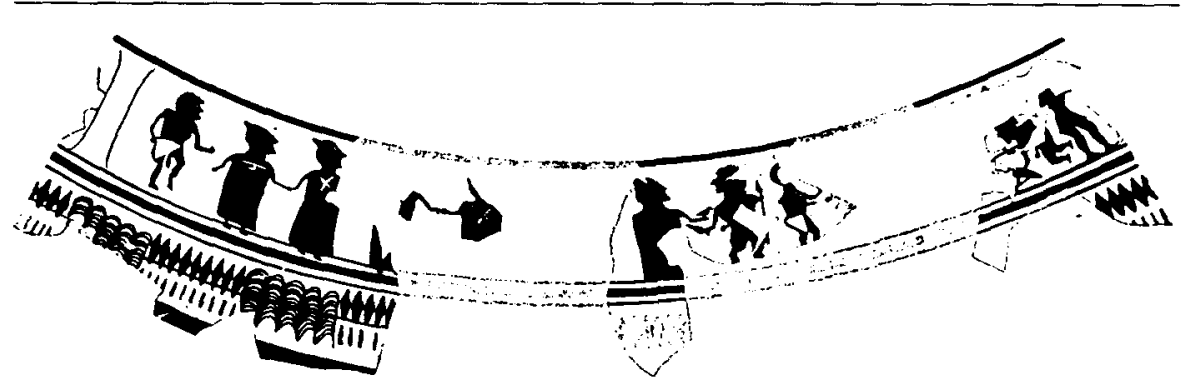

Fig. 14. "Tinaja", San Miguel de Liria (Valencia). Según Ballester Tormo.

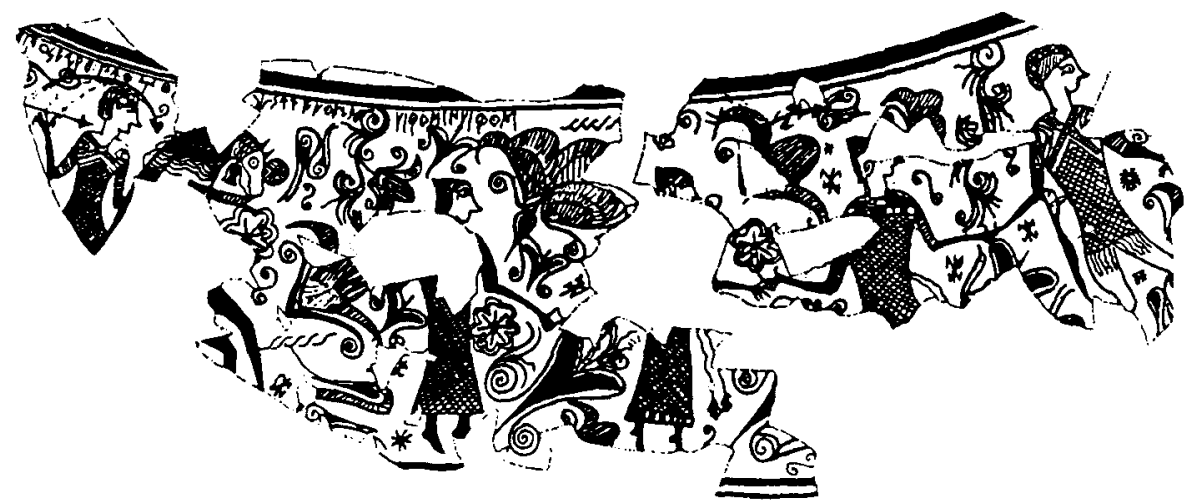

Fig. 15. San Miguel de Liria (Valencia).

midades inferiores no podemos precisar si este personaje realizaba el característico paso saltado.

Las tres mujeres visten trajes acampanados sin mangas y se cubren con tocado puntiagudo de escasa altura e inclinado hacia atrás. Dos de ellas ciñen sus cinturas con un cinturón del que cuelga un doble cordón terminado en sendas borlas, que podrían ser "Tintinabula", que sonarian con el movimiento de las danzantes. Este cordón está presente en las bailarinas de los vasos griegos de la Argólida (Courbin, 1966, 430).

Las danzantes parecen caminar de puntillas en una actitud muy semejante a la figura femenina representada en una "tinaja" de La Alcudia de Elche (Pericot, 1979, 103).

Los cuatro personajes danzan cogidos de la mano al son de un instrumento musical de viento (tuba), instrumentada por un hombre tocado con un casco terminado en una pequeña cresta superior que camina ágilmente hacia la derecha (Castelo, 1989, 17) (fig. 15).

2. La Alcudia de Elche (Alicante).-Del yacimiento alicantino debemos mencionar cuatro fragmentos cerámicos (Ramos Folqués, 1975, 
666). En los dos primeros se conservan tres figuras femeninas a izquierda que enlazan sus manos y a la vez sostienen palmas; en el tercero se observan dos bailarines masculinos que aunque no están unidos por la mano si sostienen un ramo vegetal en cada una de las manos; podríamos estar ante un nuevo movimiento de la danza de manos entrelazadas: cuando los bailarines se separan para acometer una nueva fase de la danza (fig. 16).

Estos fragmentos guardan un gran parecido con las figuraciones de la pintura vascular del período geométrico procedentes de la Argólida. En los vasos y fragmentos cerámicos recogidos por Courbin se han representado danzas colectivas masculinas (Courbin, 1966, 40, c-240) y femeninas (Courbin, 1966, pl. 41, c-210 A-B; pl. 46, c-208 A; pl. 63, c-2441 B; pl. 145, c-153; pl. 146 y pl. 147) (fig. 17).

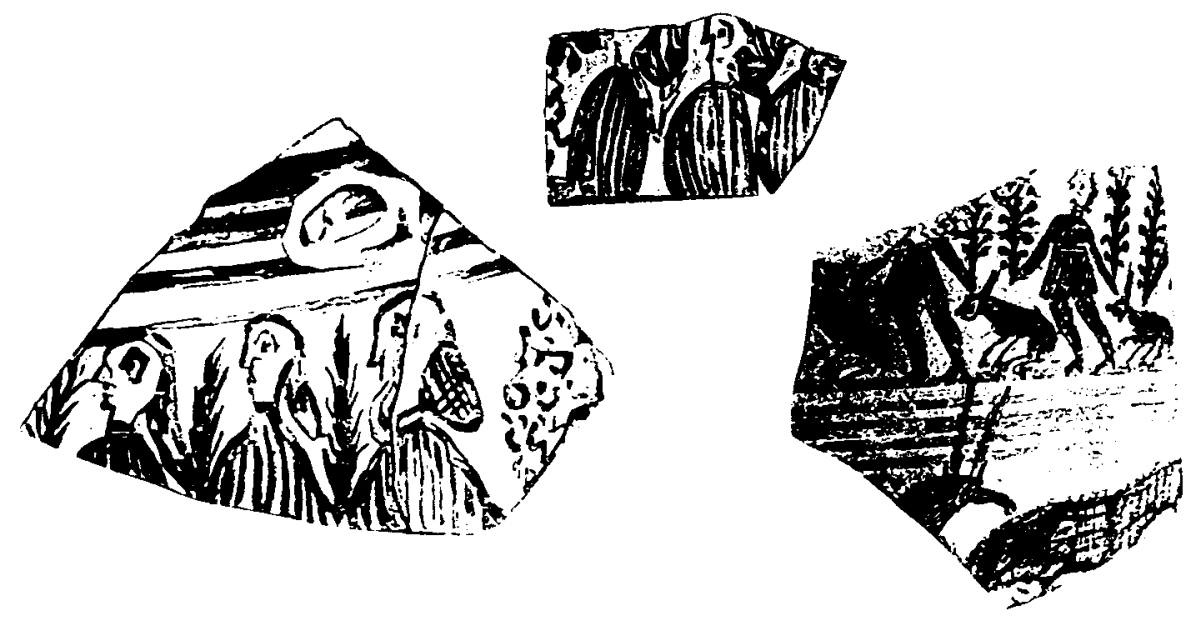

Fig. 16. Fragmentos de La Alcudia, Elche (Alicante).
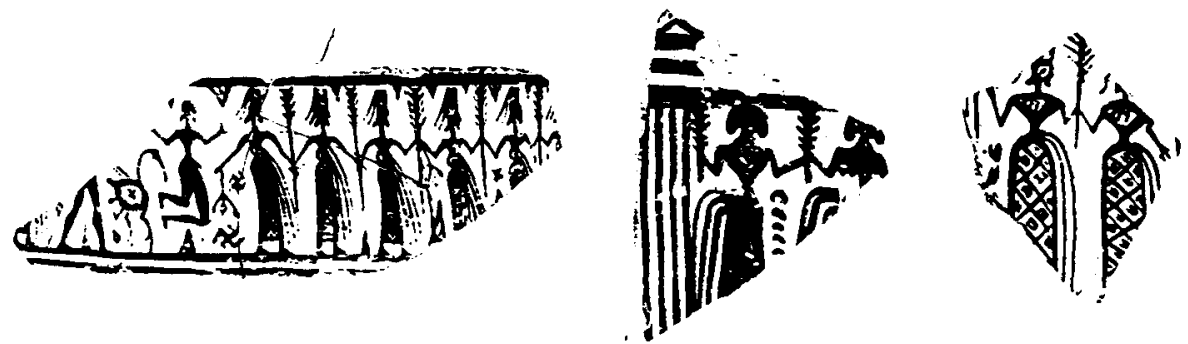

Fig. 17. Cerámicas geométricas de La Argólida. Según Courbin. 
Las danzas representadas en los vasos griegos anteriormente citados son reflejo de los pintados en los vasos ilicitanos y pueden ser un antecedente que no habia sido valorado hasta el momento.

En un fragmento cerámico pintado de La Alcudia una figura humana (probablemente femenina) baila sobre la punta de los pies y coge por la mano a otra figura que falta (Pericot, 1979, 103). La presencia de los animales y los vegetales inciden a pensar a R. Lucas, y a nosotros mismos, que se trata de una escena de danza propiciando la fecundidad y el curso de la naturaleza, el bienestar y la abundancia (Lucas, 1979, 251) (fig. 18).

3. Monastil, Elda.-Se conserva un fragmento en el que aparecen representados un hombre y una mujer cogidos de la mano, caminando a paso lento de danza a la derecha (Lucas, 1979, 275) (fig. 19).

4. En Oretania. - La existencia de estas danzas bixesuales de manos entrelazadas está documentada en un fragmento de piedra caliza depositado en el Museo Arqueológico de Jaén. La pieza fue encontrada cerca de Fuerte del Rey, junto con otros objetos arqueológicos, y publicada por Alcalá Venceslada (1930, 240). El relieve es de cara plana sin pulimentar y en él se han representado siete figuras frontales, cuatro masculinas y tres femeninas. Para Venceslada, la diferencia existente entre el tamaño de los personajes y la colocación de los mismos le hace pensar que se trata de una familia compuesta por «el matrimonio, tres hijos varones y dos hembras". Para este autor, lo difícil es interpretar el sentido $u$ objeto que pudiera tener este retrato familiar, y se plantea la posibilidad de que fuera la representación del propio escultor que la realizó que quiso dejar a la posteridad las efigies suya y de sus familiares.

Este relieve es considerado como un exvoto por E. Ruano. La autora no cree que esta representación parezca corresponder al texto de Estrabón (III, 3, 7). Considera que el mayor tamaño de la pareja central puede obedecer a cuestiones de perspectiva o a la idea de unión de la pareja humana, teoría defendida por R. Lucas (Ruano, 1987, 29) (fig. 20).

En 1987 , C. J. Pérez da a conocer en la revista Oretum un fragmento escultórico (hoy perdido) hallado en el curso de unos trabajos de reforma de una de las viviendas del grupo escolar de Almedina, que según descripción de un maestro del centro consistía en un relieve o bajorrelieve en el que se habia esculpido una hilera de figuras de pie, tal vez formando parte de una escena de danza de manos entrelazadas, en una composición muy semejante a la representada en el bajorrelieve de Fuerte del Rey (Jaén) (Pérez, 1987, 204). 


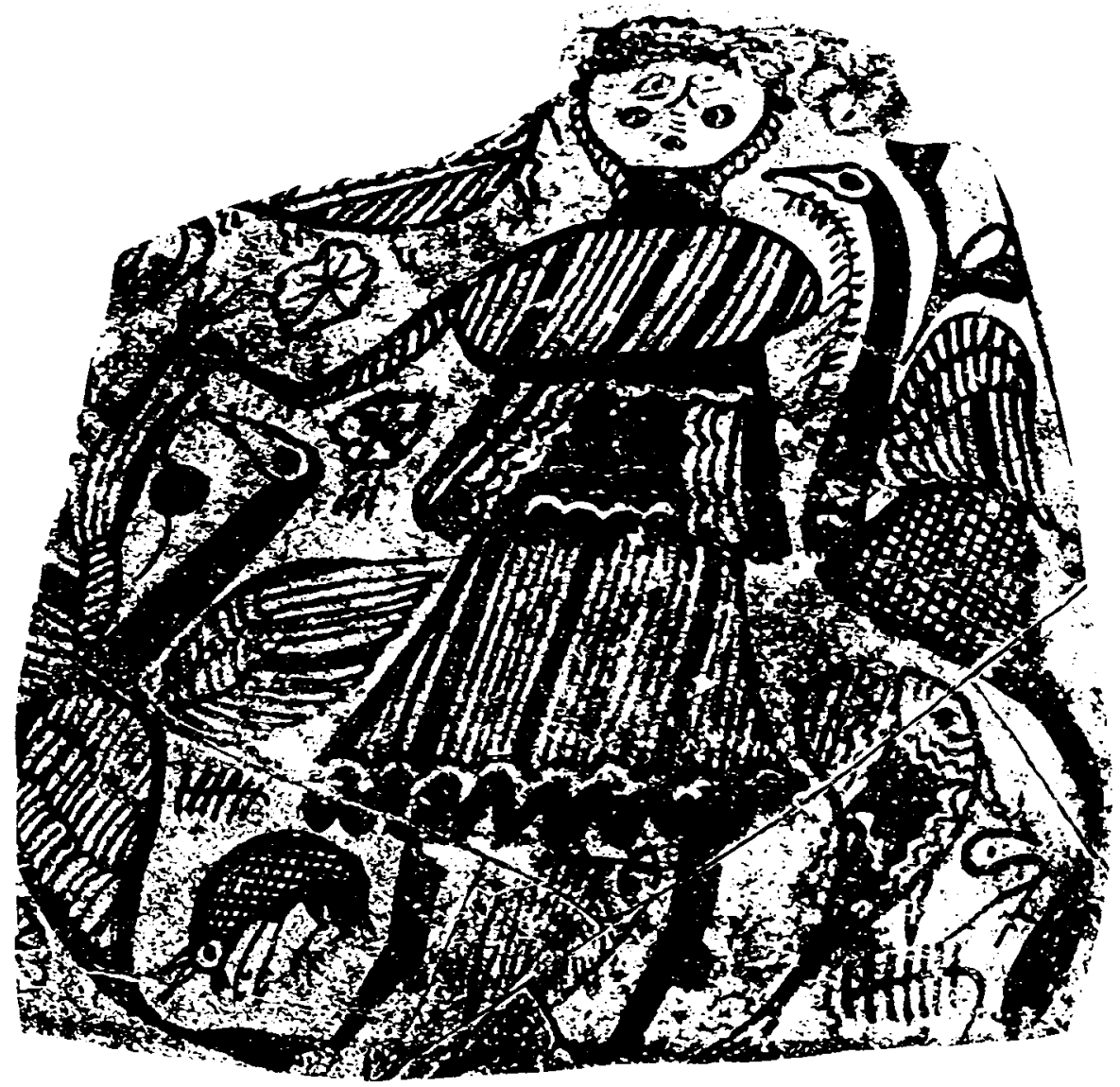

Fig. 18. Fragmento cerámico de La Alcudia, Elche (Alicante).

Aunque no pretendemos adentrarnos en el mundo romano, la costumbre de danzar unidos por las manos está atestiguada en un fragmento cerámico de terra sigillata hispánica (Draguendorf 29) procedente de los alfares riojanos; junto a los motivos geométricos se han realizado figuraciones humanas que representan a bailarines tomados de las manos (Benavente y Ortiz, 1989, 72). 


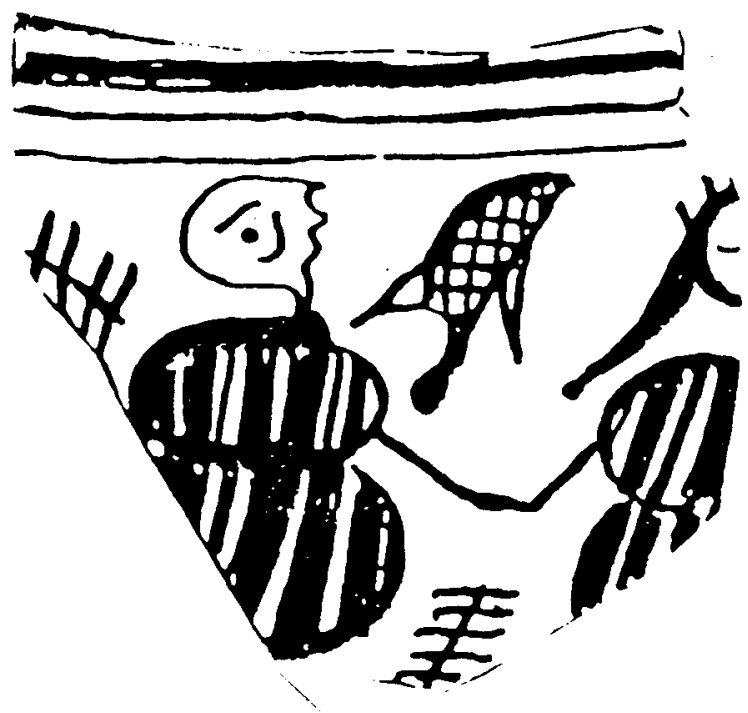

Fig. 19. Monachil, Elda (Alicante).

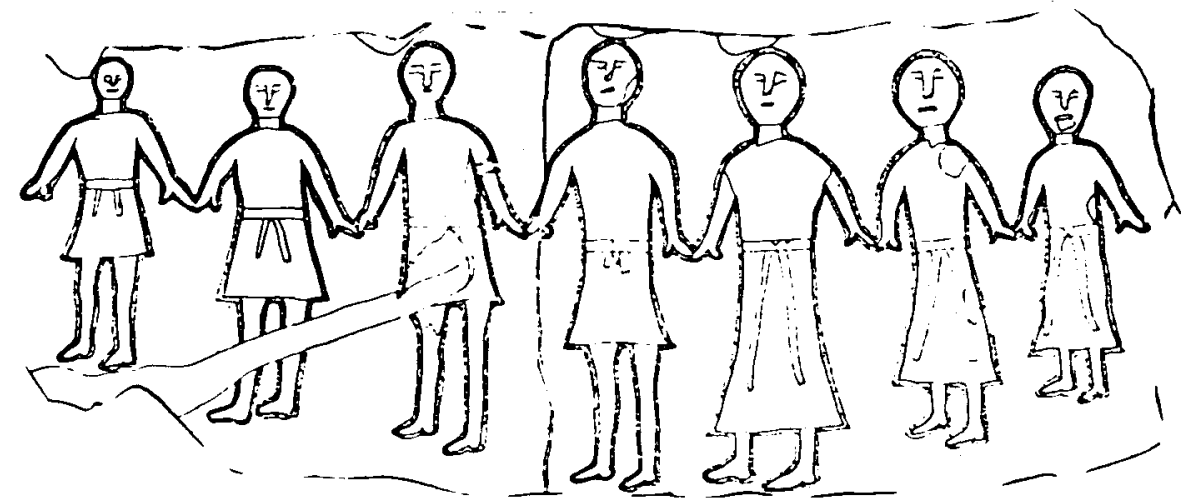

Fig. 20. Fuerte del Rey (Jaén).

\section{II) ANÁLISIS DE LA DANZA Y VARIEDADES COREOGRÁFICAS}

Según hemos podido observar a través de las dieciséis representaciones estudiadas en distintas épocas y variados soportes, el esquema primario del baile es muy sencillo; se limita a efectuar por los bailarines, cogidos de la mano, un lento movimiento hacia la derecha o la izquierda, bien en corro alrededor de un punto central o bien en línea. 
Existen numerosas combinaciones, tanto en el número de los bailarines como en la disposición en la que sitúan los hombres y mujeres; quizá estas variantes irían en función de la ceremonia que se estuviera representando.

No dudamos que los bailes se ejecutarian acompañados de sencilla instrumentación en la época más antigua. Las pinturas vasculares de Liria (Valencia) demuestran cómo en el mundo ibérico la música acompañó a estas danzas de manos (tuba y doble aulós). Aunque somos conscientes que en algunos casos estudiados el estado de fragmentación de las piezas nos impide conocer y precisar el número exacto de individuos que danzan hemos realizado unos esquemas que reflejan las variantes que nos ofrece la lectura de las imágenes (cuadro núm. 1).

Según estos esquemas, en el arte postpaleolítico es más frecuente danzar en corro alrededor de una figura central desnuda y existe un claro predominio de la ejecución por mujeres. Sólo en Peñas Cabrera alternan damas y varones.

En el Bronce Final no podemos comprobar si los personajes son masculinos o femeninos, aunque en Ategua existen dos grupos de cuatro $y$ tres figuras. Rey.

Las danzas se realizan en línea y hacia la derecha en Aldea del

El mayor número de documentos consultados pertenecen a la época ibérica, y el predomonio vuelve a ser femenino; existen triadas de hombres con mujeres (Liria, Valencia), guerreros con mujeres (Liria, Valencia), parejas de hombres (Alcudia, Elche) y parejas (Monastil, Elda y Fuertes del Rey, Jaén) integradas en grupos mixtos.

Un calatos procedente de San Miguel de Liria (Valencia) nos permite conocer la danza con gran precisión: el esquema responde al $\mathrm{H} \mathrm{H} \mathrm{H-}$ M M M M. Los bailarines, saltando sobre la pierna derecha, se mueven en hilera precedidos por una pareja de tocadores de aulós. Las mujeres simultáneamente se deslizan con pasos pequeños arrastrando los pies. La fuerza de la danza recae en el varón.

En el ambiente de Elche (Alicante), y procedente de La Alcudia, los bailarines añaden a la coreografia una hoja de palma que sujetan al entrelazar las manos. La ausencia de los pies, debido a la fragmentación de la cerámica, no permite otra interpretación. 
CUADRO I. ESQUEMA DE DANZA DE MANOS ENTRELAZADAS

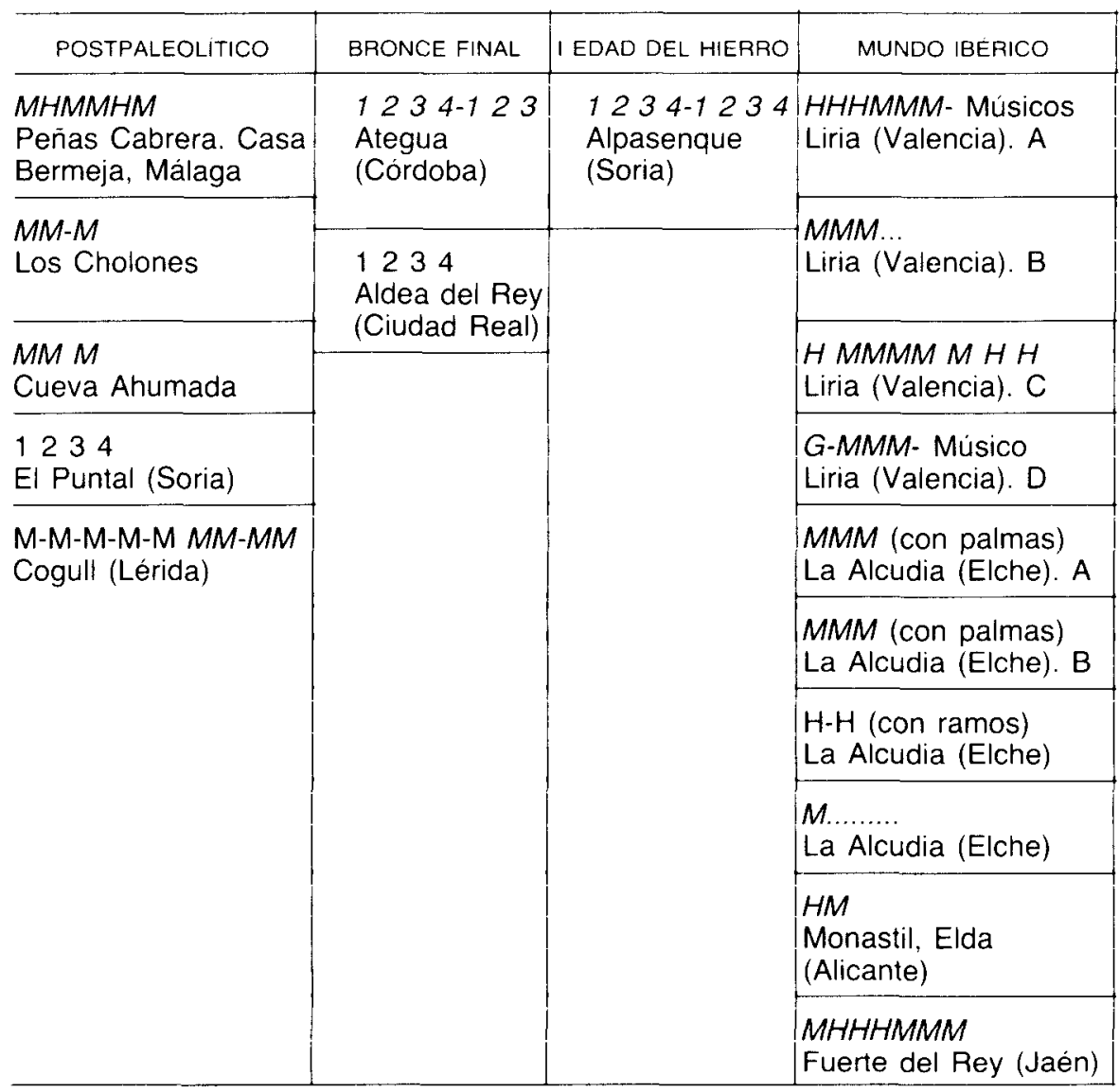

\section{III) INTERPRETACIÓN RELIGIOSA Y SOCIAL}

Son muchas las hipótesis expuestas por los investigadores para intentar resolver el significado de las danzas en el arte postpaleolítico. Dominan dos teorias en las que el sentido mágico de propiciación y fecundidad son sus objetivos. La actitud fecundante es muy estimada en el desarrollo social de la tribu y también puramente religiosa dirigida a la intercesión de la divinidad para conseguir fines propuestos.

En el Bronce Final, las danzas colectivas interpretadas por bailarines que ejecutan pasos en hilera o en corro son consideradas como bailes 
de carácter funerario debido al contexto y al soporte en que se encuentran representadas (Bendala, 1977, 192).

En la Primera Edad del Hierro, las danzas encadenadas se han interpretado como ritos de iniciación agrícola, propio de las culturas agrarias, derivadas de esquemas sociales y económicos neolíticos (Cabré y Morán, 1975, 607).

Para el mundo ibérico poseemos una más amplia información debido a la profusión de escenas de baile en las que participan hombres y mujeres. Bosch Gimpera las considera fiestas relacionadas con los ciclos agrícolas, mientras Valiente Maya y Prado Toledano resaltan su carácter funerario y su relación con las estelas del Bronce Final.

La lectura de las pinturas vasculares ibericas, y concretamente la tinaja de cuerpo britroncocónico procedente de San Miguel de Liria, sugiere a la doctora Lucas la representación de una danza en la que se efectúa un contrato o pacto (Lucas, 1979, 362)

Algunas de estas danzas representan, para R. Lucas y E. Ruano, la idea de unión de la pareja humana, ya que muchas de las escenas son danzas femeninas que conservan los viejos arquetipos de los bailes fálicos de tiempos muy remotos en los que los ritos nupciales son impulsores de la unión de seres supremos capaces de renovar cíclicamente el acto primordial de la creación (Lucas, 1979, 362, y Ruano, 1982, 28).

Sobre el posible significado de este tipo de danzas colectivas podemos observar un denominador común en todas ellas: propiciar la fecundidad y la fertilidad, ya sea de la naturaleza (animales y plantas), del difunto o de la pareja humana.

De ningún modo se puede dudar de su contenido religioso, puesto que cada vez con más frecuencia se comprueba que aquellas figuraciones cuyo sentido trasciende al puramente decorativo y están enraizadas en preocupaciones espirituales son las que, en definitiva, alcanzan más asombrosa pervivencia (Cabré y Morán, 1975, 602). 
BIBLIOGRAFIA

AcostA P., 1968: La pintura rupestre esquemática en España, Salamanca.

AlCALA VencesladA, A., 1930: "Un relieve ibérico", Boletín D. Lope de Sosa, págs. 240-241, Jaén.

Ballester Tormo, I., et alii, 1954: Cerámica del Cerro de San Miguel de Liria. Museo de la Excma. Diputación de Valencia, Corpues Vasorum Hispanorum, Madrid.

Barroso Ruiz, C., y Medina, L., 1988: "Una escena de danza en el arte rupestre postpaleolítico de la provincia de Málaga". Mainake, X. págs. 61-74, Málaga.

BenAVEnTE, J. A., y Ortiz, E., 1989: "Alcañiz el Viejo». Catálogo de la colección arqueológica de los Padres Escolapios de Alcañiz (Teruel), págs. 61-86.

Bendala Galan M., 1977: "Notas sobre las estelas decoradas del S.O. y los orígenes de Tartessos", Habis, 8, págs. 177-200, Sevilla.

BLAZQUEZ, J. M., 1975: Tartessos y la colonización fenicia en occidente, Salamanca.

- 1976: “Música, danza, competiciones e himnos en la Hispania Antigua", Revista Bellas Artes, VII, n. ${ }^{\circ} 51$, págs. 3 y ss., Madrid.

- 1977: “Música, danzas, competiciones e himnos en la España Antigua", Imagen y Mito, págs. 332-343, Madrid.

- 1983: Primitivas religiones ibéricas, t. II. Religiones prerromanas, Madrid.

BoARdmann, J., 1974: Athenian Black Figure Vases, London.

BONILLA, L., 1964: La danza en el mito y en la historia.

Cabré, E., y Moran Cabré, J. A., 1975: "Una decoración figurativa abstracta en la Edad del Hierro de la meseta oriental hispánica", XIII CAN, págs. 605-610, Zaragoza.

Coldstream, 1968: Greek Geometric Pottery, London. 
Courbin, P., 1966: Le céramique Géomètrique de L'Argolide, Bibliothèque des Écoles Françaises d'Athé nes et de Rome, Paris.

DONTAS, J., 1985: La Acrópolis y su museo, Atenas.

FAURE, P., 1984: La vida cotidiana en la Creta minóica, Barcelona.

GarCIA y Bellido A., 1944: "Música y danza entre los pueblos primitivos de España", Investigación y Progreso, 3-4, Madrid.

HOMERo, ed., 1968: La lliada, Madrid.

IMAI, A., 1977: Some Aspects of phoenician Bowols with special reference to the proto-cypriote class and the cypro-phoenician class, Michigan.

LouIS, M., 1955: "Les origenes préhistoriques de la danse", Cashiers Ligures de Préhistoire et d'Archéologie, 4, págs. 3-38, Montpellier.

LUCAS, R., 1979: "Santuarios y dioses de la baja época ibérica", Actas de la Mesa Redonda celebrada en conmemoración del $X$ aniversario de la AEAA, págs. 345-381, Madrid.

MAfFre, J. J., 1984: El arte griego. Gramática de los estilos, BarcelonaBuenos Aires-México.

Marti, B., y Hernandez, M., 1988: “El neolitic valenciá. Art rupestre i cultura material», S.I.P., Diputación de Valencia.

MAurice, L., y TAFANeL, O., 1958: Le premier âge du Fer Languedocien. T. I. Les habitats. T. II. Les necrópoles à incinération. T. III. Les tumulus. Conclusions.

MORÁN CABRÉ, 1973: "Las decoraciones primarias en la cerámica neolitica próximo-oriental, su significación y paralelismo hispánicos", XII CAN, págs. 159-168, Zaragoza.

PAPAJATSIS, N., 1985: Micenas -Epidauro-Tirinto-Nauplia, Atenas.

PARROT, A., 1960: Sumer Die Mesopotamische kunst von den Anfärigen bis zum XII Vorhrist-lichen jahrhuntert, München.

Perez, C. J., 1987: «Materiales arqueológicos del Bronce, ibéricos y romanos de Almedina (Ciudad Real). Resultados de unas prospecciones", Oretum, 3, págs. 199-207, Toledo.

Ramos Folqués, A., 1975: "En la época ibérico-púnica, o lbérico II, en La Alcudia de Elche (Alicante), XII CAN, págs. 666-667, Zaragoza.

Rosati, G., y Bunarelli, F., 1983: Museos Vaticanos. Egipcios y Etruscos, Roma.

Ruano Ruiz, E., 1977: “La danza en la antigüedad hispánica y el mundo clásico", BAEAA, 8, págs. 44-48 Madrid.

- 1982: "Restos escultóricos ibéricos de la provincia de Jaén", BAEAA, págs. 28 y ss., Madrid.

URIEL, D., 1946: "Bosquejo histórico de la música en Liria, excluyendo los tiempos actuales", Saitabi, 4, núms. 20-21, págs. 95-100, Valencia. 
Valiente Malla, J., y Prado Toledano, S., 1979: "Nueva estela decorada de Aldea del Rey (Ciudad Real)", AEspA, 52, págs. 27-32.

Zervos, Chr., 1956: L'art de la Créte néolithique et minoenne, Paris.

\section{ADDENDA}

En la cerámica neolítica de la Cueva de l'Or (Valencia) se han encontrado tres fragmentos cerámicos cardiales en los que se han identificado posibles escenas de danzas de manos entrelazadas (Marti y Hernández Pérez, 1988). 